\title{
An SVAR Approach to Evaluation of Monetary Policy in India: Solution to the Exchange Rate Puzzles in an Open Economy
}

\author{
William A. Barnett, Soumya Suvra Bhadury, Taniya Ghosh ${ }^{1}$
}

September 19, 2015

\begin{abstract}
Following the exchange-rate paper by Kim and Roubini (2000), we revisit the questions on monetary policy, exchange rate delayed overshooting, the inflationary puzzle, and the weak monetary transmission mechanism; but we do so for the open Indian economy. We further incorporate a superior monetary measure, the aggregation-theoretic Divisia monetary aggregate. Our paper confirms the efficacy of the Kim and Roubini (2000) contemporaneous restriction, customized for the Indian economy, especially when compared with recursive structure, which is damaged by the price puzzle and the exchange rate puzzle. The importance of incorporating correctly measured money into the exchange rate model is illustrated, when we compare models with no-money, simple-sum monetary measures, and Divisia monetary measures. Our results are confirmed in terms of impulse response, variance decomposition analysis, and out-of-sample forecasting. In addition, we do a flip-flop variance decomposition analysis, finding two important phenomena in the Indian economy: (i) the existence of a weak link between the nominal-policy variable and real-economic activity, and (ii) the use of inflation-targeting as a primary goal of the Indian monetary authority. These two main results are robust, holding across different time period, dissimilar monetary aggregates, and diverse exogenous model designs.
\end{abstract}

Keywords: Monetary Policy; Monetary Aggregates; Divisia monetary aggregates; Structural VAR; Exchange Rate Overshooting; Liquidity Puzzle; Price Puzzle; Exchange Rate Puzzle; Forward Discount Bias Puzzle.

JEL classification: C32, E51, E52, F31, F41

\footnotetext{
${ }^{1}$ W. A. Barnett

University of Kansas, Lawrence, Kansas, USA; and Center for Financial Stability, NY City, New York, USA

Email: barnett@ku.edu

S. Bhadury

University of Kansas, Lawrence, Kansas, USA

T. Ghosh

Indira Gandhi Institute of Development Research (IGIDR), Reserve Bank of India, Mumbai, India
} 


\section{Introduction}

Post 2008-crisis has witnessed a series of unconventional monetary policies. Such unconventional monetary policies may not be correctly modeled by the usual policy measures. It could be misleading to measure the impact of monetary policy and to track the monetary policy transmission mechanism solely through interest rates, especially when the rates are near zero. In zero lower bound environments, we find the need for an additional monetary indicator to be particularly relevant in monetary models of exchange rate determination. A theoretically grounded and properly measured indicator of money (the Divisia monetary aggregate) is a measure that can help trace the monetary transmission mechanism of unconventional policy stances by central banks. The Divisia monetary aggregates are provided for the United States by the Center for Financial Stability in New York City. We apply the Divisia monetary aggregate data available for India.

In the majority of exchange rate studies, interest rates alone plays the role of the monetary policy instrument. But Chrystal and McDonald (1995) have observed that the breakdown of the monetary models of exchange rates is associated with the troubling behavior of the simple-sum monetary aggregates. ${ }^{2}$ In this paper we emphasize the need to bring monetary aggregates back into the exchange rate models, but with better measures of money than the simple-sum accounting measures having no foundations in microeconomic aggregation theory. The following contributions are relevant. Ireland (2001a, 2001b) finds empirical support for including money growth in an interest rule for policy. In Ireland's model, money plays an informational rather than a causal role by helping to forecast future nominal interest rate. Other papers emphasizing the "information content" of monetary aggregates in predicting inflation and output include Masuch et al. (2003) and Bruggeman et al. (2005). ${ }^{3}$

Recently there has been growing interest in the use of monetary aggregates in "nowcasting" nominal GDP (gross domestic product), especially in the context of proposals for nominal GDP targeting. See, e.g., Barnett, Chauvet, and Leiva-Leon (2015).The Federal Reserve does not have monthly contemporaneous information on output, but it does have monthly observations on

\footnotetext{
${ }^{2}$ The velocity of M1, which had been stable since 1945, suddenly took a sharp downward trend after 1980 (Stone and Thornton (1987)). Leeper and Roush (2003) agree with Chrystal and McDonald that traditionally stable money demand functions were widely perceived to have become unstable.

${ }^{3}$ Nelson (2003) offers an alternative role for money. He argues that money demand depends on a long-term interest rate. Nelson's resulting specification of the Federal Reserve's interest rate rule is a dynamic generalization of the conventional Taylor rule, which excludes money. Money now has a direct effect that is independent of the shortterm interest rate. Nelson concludes that the effect is consistent with U.S. data. Anderson and Kavajecz (1994) argued for the use of monetary aggregates as either indicators and/or targets of monetary policy. Several more recent studies, such as Nicoletti-Altimari (2001), Trecoci and Vega (2002), Jansen (2004), and Assenmacher-Wesche and Gerlach (2006), have found a useful leading indicator role for monetary and credit aggregates with respect to lowfrequency trends in inflation.
} 
the money stock. Hence money may help the Federal Reserve infer current values of GDP. In particular, Barnett, Chauvet, and Leiva-Leon (2015) found a Divisia monetary aggregate to be a highly significant indicator that can be used among others to produce very accurate nowcasts of nominal GDP.

Goodfriend (1999) argues that money plays a critical role, even under an interest rate instrument policy, because credibility for a price-path target depends upon the central bank's ability to manage the stock of money to enforce the objective. In equilibrium, money does not play a causal role in Goodfriend's view, but is essential for establishing the credibility that allows the central bank to determine expected inflation. Similar positions have been taken by such authors as Christiano et al. (2007) and Cochrane (2007). For example, Cochrane (2007) argues that monetary aggregates may play a nominal anchor role, whereby the announcement of a reference trajectory for future monetary growth may help agents form expectations about future prices. In comparisons among models without money and models with interactions between money and the funds rate, Leeper and Roush (2003) have found large and significant effects of money on the estimated real and nominal effects of policy. Hence money provides information important to identifying monetary policy-transmission not contained solely in the Federal fund rate.

One of this paper's contributions is to introduce the theoretically grounded Divisia monetary aggregate into the Kim and Roubini (2000) setup. Divisia monetary aggregates are directly derived from microeconomic aggregation theory, as shown by Barnett (1980), and are consistent with Diewert's (1976) criteria for inclusion in the "superlative index number class." Divisia monetary aggregates measure the flow of the monetary services derived from a collection of monetary assets, while permitting those component assets to be imperfectly substitutable, as compared to the simple sum aggregates, which assume all monetary assets to be perfectly substitutable. A large literature exists on the empirical and theoretical merits of those aggregation theoretic aggregates. See, e.g., Barnett and Serletis (2000), Barnett and Chauvet 2011), and Barnett (2012), along with Schunk (2001), Drake and Mills (2005), Chrystal and McDonald (1995), and Belongia and Ireland (2012), among many others. Of particular relevance is Barnett and Kwag (2006), who find that introducing Divisia aggregates into money market equilibrium conditions improves the forecasting performance of monetary models of exchange rates. A source of much of that literature is the online library maintained by the Center for Financial Stability in New York City at http://www.centerforfinancialstability.org/amfm.php.

Almost 15 years post publication of Kim and Roubini (2000), we revisit similar small open economy structural vector auto-regression (SVAR) models. But we do so with data from India: an economy that is relatively open, one of the biggest importers of oil, on the transition path to becoming one of the emerging Asian economies, a member of the G20 nations, and governed by a central bank that avoids intervening heavily in the foreign exchange market. Our model builds on the Kim and Roubini (2000) model and is customized for the Indian economy. 
The paper examines the impact of monetary policy shocks on the price level, output, and exchange rate. In particular, we explore whether monetary policy shocks have a delayed and gradual effect on the price levels, whether a shock to the policy has a small and temporary or a substantive and permanent effect on the output, and whether monetary policy serves to dampen output and price fluctuation for the Indian economy. Finally we explore whether there is existence of delayed exchange rate overshooting. The interest rate equation in our model is the policy reaction function of the central bank with the money/interbank rate for India being the interest rate. The monetary aggregate equation is a money demand equation, dependent upon output, price, and interest rates.

We compare across models that contain no money, with interbank rates of interest being the only monetary policy variable. Then we add simple-sum money into our model along with the policy rate variables, and finally Divisia money. We extensively compare across these three sets of models. We also compare across the monetary models at different levels of aggregation.

We also provide a variance decomposition analysis. For models with money, especially Divisia money, the policy variable is found to explain more of the exchange rate fluctuation than the models containing simple-sum money or the models without money. Finally, we test the out-ofsample forecasting power of the different models.

Our result shows that the models with monetary aggregates perform significantly better than the no-money models, and that models with the Divisia monetary aggregate outperform their simplesum counterpart.

\section{The Indian Economy at a Glance}

The following figures provide a brief overview of the Indian economy since 1992.

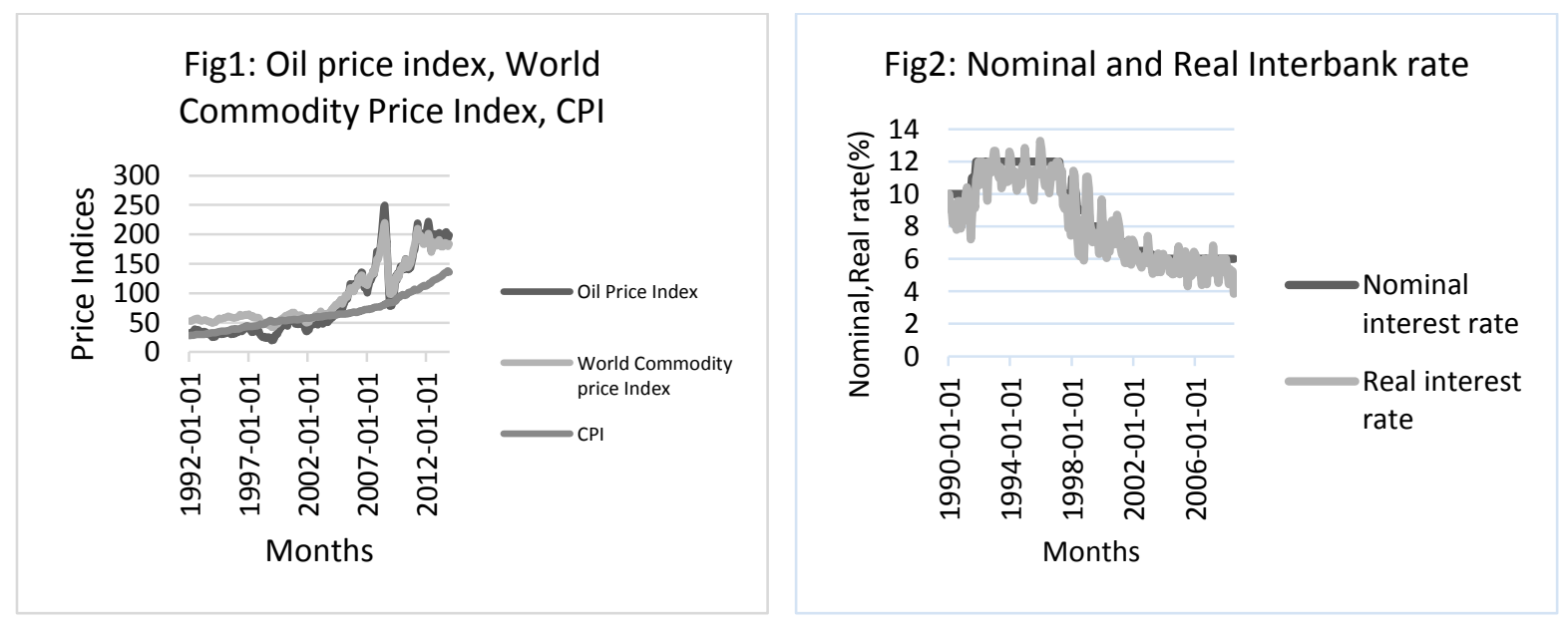



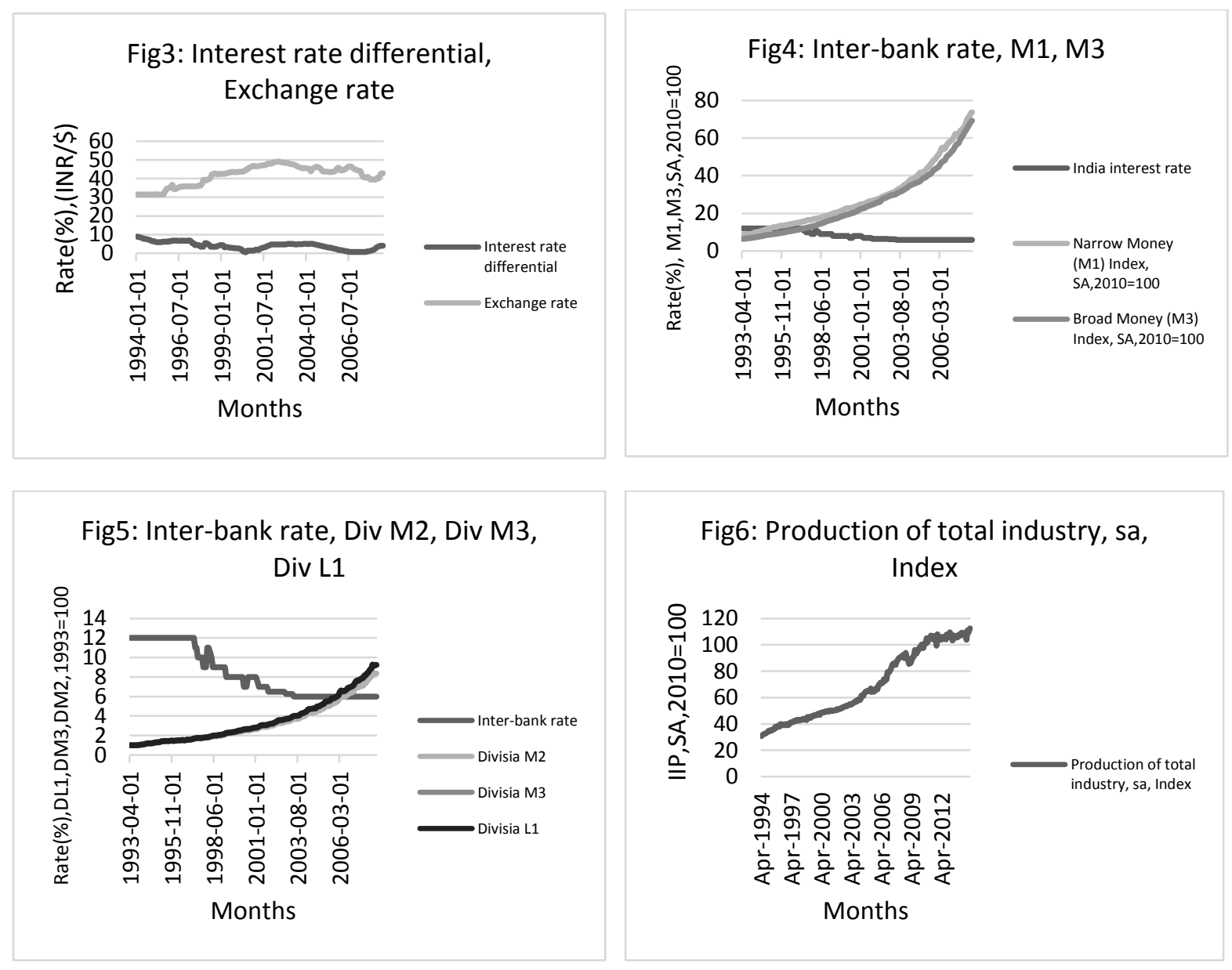

Figure 1 shows the Indian economy experienced very high inflation during the last 24 years. The CPI (consumer price index) between the first quarter of 1992 and the last quarter of 2013 rose by 384 percent. The average was a 17 percent price rise. However, from the first quarter of 1992 to the first quarter of 2000 , CPI rose by $89 \%$. On an average, there was a 9 percent price rise every year during that time period.

Figure 2 shows that loose monetary stance was a dominant feature of the economy between 1992 and 1997.

Figure 3 displays the interest rate differential between India and U.S. and the exchange rate of the India rupee relative to the US dollar. The figure suggests that the movements of the nominal exchange rate appear to have followed the interest rate differential with a lag.

Figure 4 displays the accelerated growth in the money supply for both M1 and M3 during a period of loosening of inter-bank rates. 
Figure 5 displays the liquidity of the Indian economy using the theoretically grounded Divisia monetary aggregates. Divisia reflects much liquidity injection into the economy, but not as much as the simple-sum monetary aggregates would imply.

Figure 6 displays the production of total industry (IIP) for India. The period of highest industrial growth was between 2002 and 2007, after which the growth slowed dramatically.

\section{Estimation}

\subsection{Model}

The system of equations representing the SVAR dynamic structural models can be written in the vector form as

$$
\mathbf{B}_{0} \mathbf{y}_{t}=\mathbf{k}+\mathbf{B}_{1} \mathbf{y}_{t-1}+\mathbf{B}_{2} \mathbf{y}_{t-2}+\cdots+\mathbf{B}_{p} \mathbf{y}_{t-p}+\mathbf{u}_{t}
$$

where $\mathbf{y}_{t}$ is an $n \times 1$ vector, $\mathbf{k}$ is an $n \times 1$ vector of constants, $\mathbf{u}_{t}$ is an $n \times 1$ structural disturbances vector. The disturbances $\mathbf{u}_{t}$ are serially and mutually uncorrelated, while $p$ denotes the number of lags. The matrix $\mathbf{B}_{0}$ is defined by

$$
\mathbf{B}_{0}=\left[\begin{array}{cccc}
1 & -B_{12}^{(0)} & \cdots & -B_{1 n}^{(0)} \\
\vdots & \vdots & \cdots & \vdots \\
\vdots & \vdots & \cdots & \vdots \\
-B_{n 1}^{(0)} & -B_{n 2}^{(0)} & \cdots & 1
\end{array}\right]
$$

while $\mathbf{B}_{t}$ is an $n \times n$ matrix whose row $i$, column $j$ element is $B_{i j}^{\left({ }^{(s)}\right.}$ for $s=1,2, \cdots p$.

If each side of (3.1) is pre-multiplied by $\mathbf{B}_{0}^{-1}$, the result is

$$
\mathbf{y}_{t}=\mathbf{c}+\boldsymbol{\varphi}_{1} \mathbf{y}_{t-1}+\boldsymbol{\varphi}_{2} \mathbf{y}_{t-2}+\cdots+\varphi_{p} \mathbf{y}_{t-p}+\boldsymbol{\varepsilon}_{t},
$$

where $\mathbf{c}=\mathbf{B}_{0}^{-1} \mathbf{k}$,

$$
\begin{aligned}
& \boldsymbol{\varphi}_{s}=\mathbf{B}_{0}^{-1} \mathbf{B}_{s}, \text { for } s=1,2,3, \cdots, p, \\
& \boldsymbol{\varepsilon}_{t}=\mathbf{B}_{0}^{-1} \mathbf{u}_{t} .
\end{aligned}
$$


Thus the VAR, equation (3.3), can be viewed as the reduced form of the dynamic structural model, (3.1). The structural disturbances, $\mathbf{u}_{t}$, and the reduced form residuals, $\boldsymbol{\varepsilon}_{t}$, are related by

$$
\mathbf{u}_{t}=\mathbf{B}_{0} \boldsymbol{\varepsilon}_{t}
$$

To estimate the parameters from the structural form equations requires that the model be either exactly identified or over-identified. A necessary condition for exact identification is that there be the same number of parameters in $\mathbf{B}_{0}$ and $\mathbf{D}$ as in $\boldsymbol{\Omega}$, where $\mathbf{D}=\mathrm{E}\left(\mathbf{u}_{t} \mathbf{u}_{t}^{\prime}\right)$ is the covariance matrix of the structural disturbances, and $\boldsymbol{\Omega}=\mathrm{E}\left(\boldsymbol{\varepsilon}_{t} \boldsymbol{\varepsilon}_{t}^{\prime}\right)$ is the covariance matrix of the reduced form disturbances, $\boldsymbol{\varepsilon}_{t}$. Under this condition, called the order condition, it is possible to recover the structural parameters from the reduced form. In addition the model must satisfy the rank condition, as can be assured by using the Cholesky decomposition of the reduced form innovations, as proposed by Sims (1980). The result is a recursive structure identifying the model. There are other methods, such as structural VAR, which can be non-recursive, with restrictions imposed on instantaneous relations among the variables. Those restrictions can come from economic theory (see, e.g., Bernanke (1986)).

The following results from the above definitions:

$$
\boldsymbol{\Omega}=\mathbf{E}\left(\boldsymbol{\varepsilon}_{t} \boldsymbol{\varepsilon}_{t}^{\prime}\right)=\mathbf{B}_{0}^{-1} \mathbf{E}\left(\mathbf{u}_{t} \mathbf{u}_{t}^{\prime}\right)\left(\mathbf{B}_{0}^{-1}\right)^{\prime}=\mathbf{B}_{0}^{-1} \mathbf{D}\left(\mathbf{B}_{0}^{-1}\right)^{\prime} .
$$

Since $\boldsymbol{\Omega}$ is symmetric, it has $\frac{n(n+1)}{2}$ parameters. In the SVAR literature, $\mathbf{D}$ is the diagonal matrix having $n$ parameters. Hence $\mathbf{B}_{0}$ can have no more than $\frac{n(n-1)}{2}$ restrictions for exact identification and is a triangular matrix for the VAR with Cholesky decomposition of the innovations.

For an exactly identified model, a two-step maximum likelihood estimation procedure can be employed under the assumption that the structural errors are multivariate normal. The procedure results in full information maximum likelihood (FIML) estimation of the SVAR model. First, $\mathbf{\Omega}$ is estimated as

$$
\hat{\mathbf{\Omega}}=(1 / T) \sum_{t=1}^{T} \hat{\boldsymbol{\varepsilon}}_{t} \hat{\boldsymbol{\varepsilon}}_{t}^{\prime},
$$

with $\hat{\boldsymbol{\varepsilon}}_{t}$ being the estimated residuals. Estimates of $\mathbf{B}_{0}$ and $\mathbf{D}$ are then obtained by maximizing the $\log$ likelihood, conditional on $\hat{\mathbf{\Omega}}$. But when the model is over-identified, the two-step procedure does not produce the FIML estimator for the SVAR model. The two-step estimates are consistent but not efficient, since they do not take the over-identification restrictions into 
account, when estimating the reduced form. For an over-identified system, we estimate the VAR model both without additional restrictions and with additional restrictions to obtain the 'unrestricted' and 'restricted' variance-covariance matrices, respectively. In each case, we maximize the likelihood function. The difference between the determinants of the restricted and unrestricted variance-covariance matrices is distributed $\chi^{2}$ with degrees of freedom equal to the number of additional restrictions resulting from exceeding the just identified system. The $\chi^{2}$ test statistic is used to test the restricted system.(see, e.g., Hamilton (1994)).

Ideally, the restrictions imposed to identify a SVAR model would result from a fully specified macroeconomic model. In practice, however, this is rarely done. Instead, the more common approach is to impose a set of identification restrictions that are broadly consistent with the economic theories and provide sensible outcomes. Generally, the metric used is whether the behavior of the dynamic responses of the model accords with the economic theories. Given a set of variables of interest and criteria for model selection, identification restrictions can be imposed in a number of available ways. Most commonly, these involve restrictions on $\mathbf{B}_{0}$ or on $\mathbf{B}_{0}^{-1}$, or restrictions on the long run behavior of the model.

\subsection{Identification}

We use a 7-variable VAR including the world oil price index and alternatively the commodity price index (oilp or wpcom), the federal fund rate (rfed), the India index of industrial production (iip), the level of inflation in the domestic small open economy $(\pi)$, a domestic monetary aggregate (MD), nominal short-term domestic interest rate (rdom) producing the monetary policy shocks (MP), and the nominal exchange rate in domestic currency per US dollar (ER). ${ }^{4}$ Our identification scheme based on equation (3.7) is given below.

$$
\left(\begin{array}{c}
u_{t}^{\text {oil or wcom }} \\
u_{t}^{\text {rfed }} \\
u_{t}^{i i p} \\
u_{t}^{\pi} \\
u_{t}^{M D} \\
u_{t}^{M P} \\
u_{t}^{E R}
\end{array}\right)=\left(\begin{array}{ccccccc}
1 & 0 & 0 & 0 & 0 & 0 & 0 \\
b_{21} & 1 & 0 & 0 & 0 & 0 & 0 \\
b_{31} & b_{32} & 1 & 0 & 0 & 0 & 0 \\
b_{41} & 0 & b_{43} & 1 & 0 & 0 & 0 \\
0 & b_{52} & b_{53} & b_{54} & 1 & b_{56} & b_{57} \\
b_{61} & 0 & 0 & 0 & b_{65} & 1 & b_{67} \\
b_{71} & b_{72} & b_{73} & b_{74} & b_{75} & b_{76} & 1
\end{array}\right)\left(\begin{array}{c}
\varepsilon_{t}^{\text {oil or wcom }} \\
\varepsilon_{t}^{\text {rfed }} \\
\varepsilon_{t}^{i i p} \\
\varepsilon_{t}^{\pi} \\
\varepsilon_{t}^{M D} \\
\varepsilon_{t}^{M P} \\
\varepsilon_{t}^{E R}
\end{array}\right)
$$

\footnotetext{
${ }^{4}$ Differencing of variables does not provide gain in asymptotic efficiency and may cause loss of information regarding the co-movements, such as cointegrating relationships between variables. Hence, we use a VAR in levels.
} 
Here $\mathbf{u}_{t}$ is the vector of structural innovations, while $\boldsymbol{\varepsilon}_{t}$ is the vector of errors from the reduced form equations. This specification is similar to Kim and Roubini (2000), but modified to fit the Indian economy better and to permit comparisons of different monetary aggregates.

Restrictions on $\mathbf{B}_{0}$ are motivated in the following way. As in Kim and Roubini (2000), we have a contemporaneously exogenous world shock variable, alternatively captured using the world commodity price index and world price index. Although none of the domestic variables can affect the world variables contemporaneously, they can do so over the time. Similarly, the federal funds rate in the U.S. is only affected by the world event shocks. No domestic events have enough impact to influence the policy variables of the largest economy in the world. As in Kim and Roubini (2000), it is necessary to include these two variables to isolate and control the exogenous component of monetary policy shocks.

A further behavioral restriction often imposed is that certain variables respond slowly to movements in financial and policy variables. So, for example, output and prices do not respond contemporaneously to changes in domestic monetary policy variables and exchange rates. Real activity, like industrial production, responds to domestic price and financial signals with a lag, as a result of high adjustment costs to production. However, industrial production of a small, open, economy is deeply impacted by world or outside shocks. Inflation and industrial production are affected by the world shock. People's willingness to hold cash given by the money demand function usually depends on real income and the domestic interest rate. To explore how different monetary aggregates compare in identifying the monetary policy for a small open economy and how they contribute to explaining the exchange rate movements, we assume that the money demand function also depends on the foreign (US) interest rate and the prevailing exchange rates.

The monetary policy equation is the monetary authority's reaction function, which sets the interest rate after observing the current value of money supply, the interest rate, and the exchange rate.

The data are in monthly frequency for the sample period January 2000- January 2008. We choose that sample period for India, because of the financial market deregulation that occurred post-1990s. Also the way the central bank of India sets policy rates has undergone major transformation post-2000. The foreign crude oil price index is an arithmetic average of three spot prices; Brent, West Texas Intermediate, and Dubai Fateh, obtained from the database of Index Mundi. All commodity price indexes, fuel and non-fuel, and IMF commodities are obtained from the Econ Stats website. The Indian variables --- the index of total industry production, the consumer price index, the interest rate (call moneylinterbank rate), the simple-sum monetary aggregate indexes (M1) and (M3), and the nominal exchange rate (Indian rupee per USD) --- 
along with the US federal funds rate, are obtained from the OECD database. ${ }^{5}$ The Divisia monetary aggregates, (DM2), (DM3), and (DL1), are obtained from Ramachandran, Das, and Bhoi (2010).

The series are seasonally adjusted by the official sources except for the Indian Divisia, the world oil prices, and the world price of commodities, which are seasonally adjusted using frequency domain deseasonalization in RATS (see Doan (2013)). All variables are in logarithms except for the interest rates. The inflation $(\pi)$ is calculated as the annual change in the log of consumer prices. Monthly VAR is estimated using 6 lags. The lags are selected by the sequential likelihood ratio test in RATS (see Doan (2013)). The results from sequential likelihood ratio test are presented in table $\mathrm{A}$ in the appendix.

\subsection{Impulse Response Analysis}

We evaluate the models given in Table 1 relative to the four prevalent puzzles that have plagued the empirical exchange rate literature: namely, the liquidity puzzle, the price puzzle, the exchange rate puzzle, and the forward discount bias puzzle. In this section we also provide three impulse response graphs, one for the recursive model with no money (Model 16), the SVAR model with simple-sum M3 (Model 2), and the SVAR model with Divisia M3 (Model 1). ${ }^{6}$

\footnotetext{
${ }^{5}$ The Indian monetary aggregates are defined as follows: M2 = currency with the public + demand deposits with banks + other deposits with the Reserve Bank of India + savings deposits with banks + term deposits with contractual maturity of up to and including one year with banks + certificate of deposits issued by banks; M3 = M2 + term deposits with contractual maturity of over one year with banks + call borrowings from non-depository financial corporations by banks; and L1 = M3 + all deposits with the Post Office Savings Banks (excluding National Savings Certificates).

${ }^{6}$ The results with other models are available upon request.
} 


\begin{tabular}{|c|c|c|}
\hline \multicolumn{3}{|c|}{ Table 1: Recursive and Non-recursive Model Setup ${ }^{7}$} \\
\hline \multicolumn{3}{|c|}{ SVAR Model [Non-Recursive (NR) Structure] } \\
\hline Model 1 & $\{$ oilp, rfed, iip, $\pi, \mathrm{DM} 3$, rdom, ER $\}$ & (NR, OIL, DM3) \\
\hline Model 2 & $\{$ oilp, rfed, iip, $\pi, \mathrm{M} 3$, rdom, ER $\}$ & (NR, OIL, M3) \\
\hline Model 3 & $\{$ oilp, rfed, iip, $\pi, \mathrm{M} 1$, rdom, ER $\}$ & (NR, OIL, M1) \\
\hline Model 4 & $\{$ oilp, rfed, iip, $\pi$, DL1, rdom, ER $\}$ & (NR, OIL, DL1) \\
\hline Model 5 & $\{$ oilp, rfed, iip, $\pi$, DM2, rdom, ER $\}$ & $(\mathrm{NR}, \mathrm{OIL}, \mathrm{DM} 2)$ \\
\hline Model 6 & $\{$ wcom, rfed, iip, $\pi, \mathrm{DM} 3$, rdom, ER $\}$ & (NR, COM, DM3) \\
\hline Model 7 & $\{$ wcom, rfed, iip, $\pi, \mathrm{M} 3$, rdom, ER $\}$ & (NR, COM, M3) \\
\hline Model 8 & $\{$ wcom, rfed, iip, $\pi$, M1, rdom, ER $\}$ & $(\mathrm{NR}, \mathrm{COM}, \mathrm{M} 1)$ \\
\hline Model 9 & $\{$ wcom, rfed, iip, $\pi$, DL1, rdom, ER $\}$ & (NR, COM, DL1) \\
\hline Model 10 & $\{$ wcom, rfed, iip, $\pi$, DM2, rdom, ER $\}$ & (NR,COM,DM2) \\
\hline \multicolumn{3}{|c|}{ VAR Models with Cholesky Decomposition [Recursive (R) Structure] } \\
\hline Model 11 & $\{$ oilp, rfed, iip, $\pi$, DM3, rdom, ER $\}$ & (R, OIL, DM3) \\
\hline Model 12 & $\{$ oilp, rfed, iip, $\pi, \mathrm{M} 3$, rdom, ER $\}$ & $(\mathrm{R}, \mathrm{OIL}, \mathrm{M} 3)$ \\
\hline Model 13 & $\{$ oilp, rfed, iip, $\pi, \mathrm{M} 1$, rdom, ER $\}$ & $(\mathrm{R}, \mathrm{OIL}, \mathrm{M} 1)$ \\
\hline Model 14 & $\{$ oilp, rfed, iip, $\pi$, DL1, rdom, ER $\}$ & $(\mathrm{R}, \mathrm{OIL}, \mathrm{DL} 1)$ \\
\hline Model 15 & $\{$ oilp, rfed, iip, $\pi, \mathrm{DM} 2$, rdom, ER $\}$ & (R, OIL, DM2) \\
\hline Model 16 & $\{$ oilp, rfed, iip, $\pi$, rdom, ER $\}$ & $(\mathrm{R}, \mathrm{OIL}, \mathrm{X})$ \\
\hline
\end{tabular}

We now briefly define the four puzzles that have been widely prevalent in the exchange rate literature:

(1) Theory predicts that an increase in the domestic interest rates should lead to an impact appreciation of the exchange rate (exchange rate overshooting) and thereafter depreciation of the currency in line with the uncovered interest parity. Higher return on investments from the increase in domestic interest rates would lead to a higher demand for domestic currency and hence appreciating of the domestic currency relative to the foreign currency. The exchange rate puzzle occurs when a restrictive domestic monetary policy leads to an impact depreciation of domestic currency.

(2) Alternatively, if the domestic currency appreciates, it does so for a prolonged period of time, violating the uncovered interest parity condition. That phenomenon is known as the forward discount bias puzzle or delayed overshooting.

(3) The liquidity puzzle results, when a money market shock is associated with increases in the interest rate. This phenomenon reflects the absence of the liquidity effect, defined by negative correlation between monetary aggregates and interest rates.

(4) The price puzzle is a phenomenon by which a contractionary monetary policy shock, identified with an increase in interest rates, leads to a persistent rise in price level.

\footnotetext{
${ }^{7}$ The codes in parentheses represent the model structure (Non-Recursive or Recursive), the world variable (World price of oil or World Commodity price), and the monetary aggregate (DM3, M3, M1, DL1, DM2, or X, which designates no money).
} 
Table 2 summarizes the main results that we obtain from models with Cholesky ordering and from the SVAR models.

\begin{tabular}{|c|c|c|c|c|}
\hline \multicolumn{5}{|c|}{ Table 2: Model Setup Analysis in Terms of Puzzles } \\
\hline Model \& Code & $\begin{array}{l}\text { Liquidity } \\
\text { Puzzle }\end{array}$ & Price Puzzle & $\begin{array}{l}\text { Exchange Rate } \\
\text { Puzzle }\end{array}$ & $\begin{array}{l}\text { Forward Discount } \\
\text { Bias Puzzle }\end{array}$ \\
\hline 1 (NR,OIL,DM3) & Slight to none & None & None & None \\
\hline 2 (NR,OIL,M3) & Insignificant & None & Slight to None & None \\
\hline 3 (NR,OIL,M1) & Yes & Yes & None & None \\
\hline 4 (NR,OIL,DL1) & Slight to none & None & None & None \\
\hline 5 (NR,OIL,DM2) & Slight to none & None & None & None \\
\hline 6(NR,COM,DM3) & Slight to none & Slight to none & None & None \\
\hline 7 (NR,COM,M3) & Insignificant & Insignificant & None & None \\
\hline 8 (NR,COM,M1) & Insignificant & None & None & None \\
\hline 9 (NR,COM,DL1) & Insignificant & Insignificant & None & None \\
\hline 10(NR,COM,DM2) & Insignificant & None & None & None \\
\hline 11 (R,OIL,DM3) & Yes & Yes & Slight to None & Yes \\
\hline 12 (R,OIL,M3) & Insignificant & Yes & Yes & Yes \\
\hline 13 (R,OIL,M1) & None & Yes & Yes & Yes \\
\hline 14 (R,OIL,DL1) & Yes & Yes & Slight to None & Yes \\
\hline 15 (R,OIL,DM2) & Yes & Yes & Slight to None & Yes \\
\hline $16(\mathrm{R}, \mathrm{OIL}, \mathrm{X})$ & Yes & Yes & Yes & Yes \\
\hline
\end{tabular}

We encounter almost all the puzzles in the recursive models (models 11-16). Figure 7 displays the impulse response graphs for a recursive model with no money. The effect of monetary policy shocks is normalized, so that interest rates increase by one percentage point in the first month. A one percentage point increase in the interest rate leads to an impact depreciation of the currency and persistent depreciation thereafter, producing both the exchange rate puzzle and the forward discount bias puzzle. There is also a persistent rise in inflation from a contractionary monetary policy shocks, producing the price puzzle. 
Figure 7: Impulse Responses for Monetary Policy Shocks (Recursive Model)

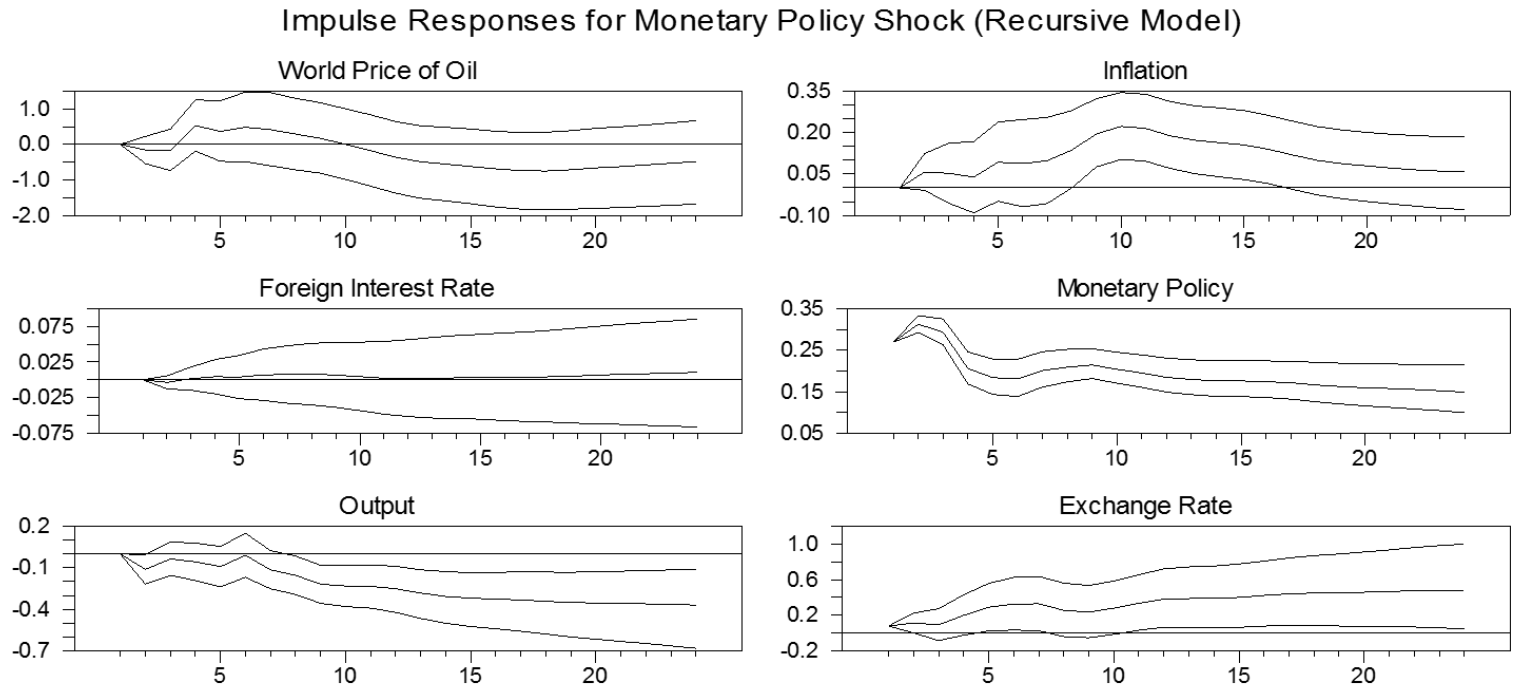

In contrast, the SVAR (non-recursive) models reflect the Indian monetary policy more acceptably. Most of the puzzles are eliminated, and the results are robust. We see the intensity of the liquidity effect. Exchange rate overshooting is more pronounced for the model with Divisia M3 than with simple sum M3.

Figure 8: Impulse Responses for Monetary Policy Shocks (Non-Recursive Model)

Model with Divisia M3 (Model1)
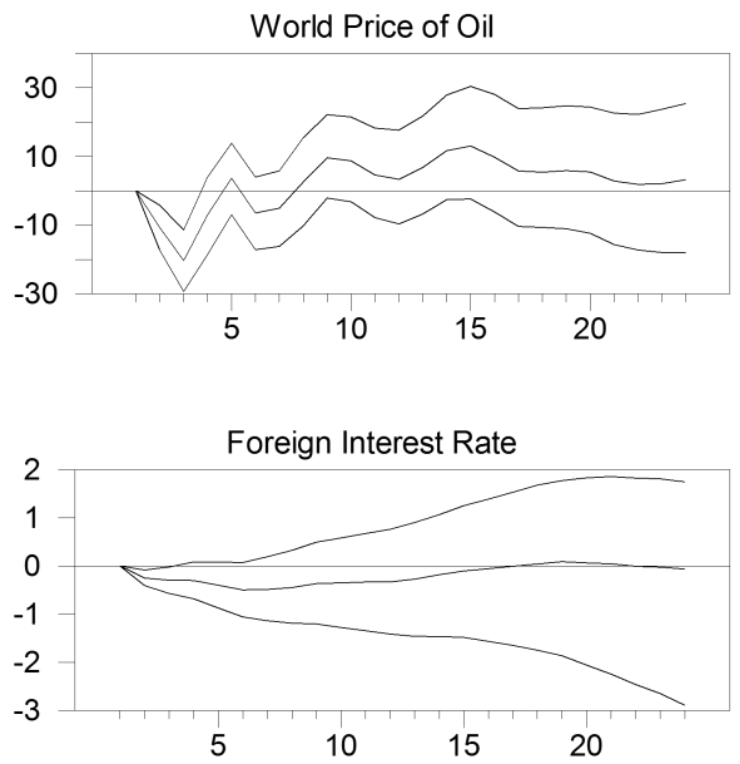

Model with M3 (Model 2)

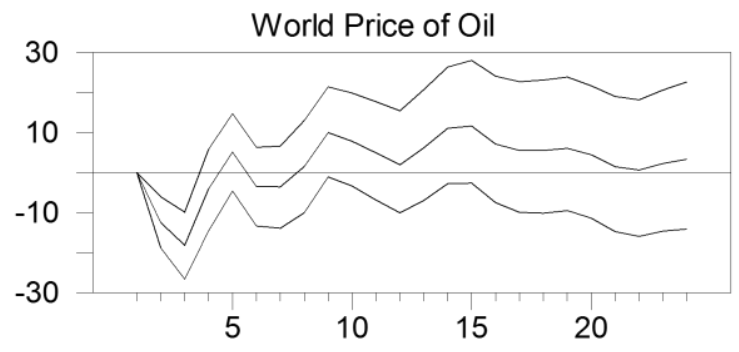

Foreign Interest Rate

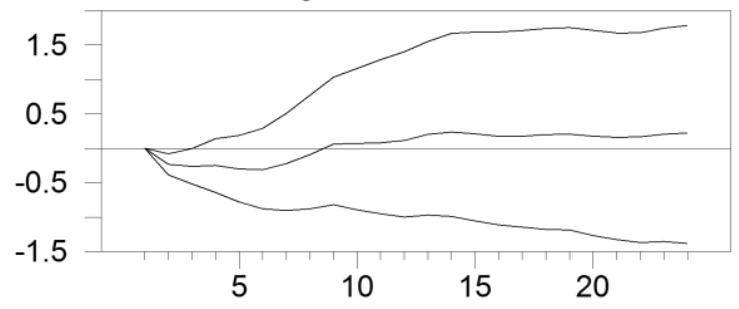



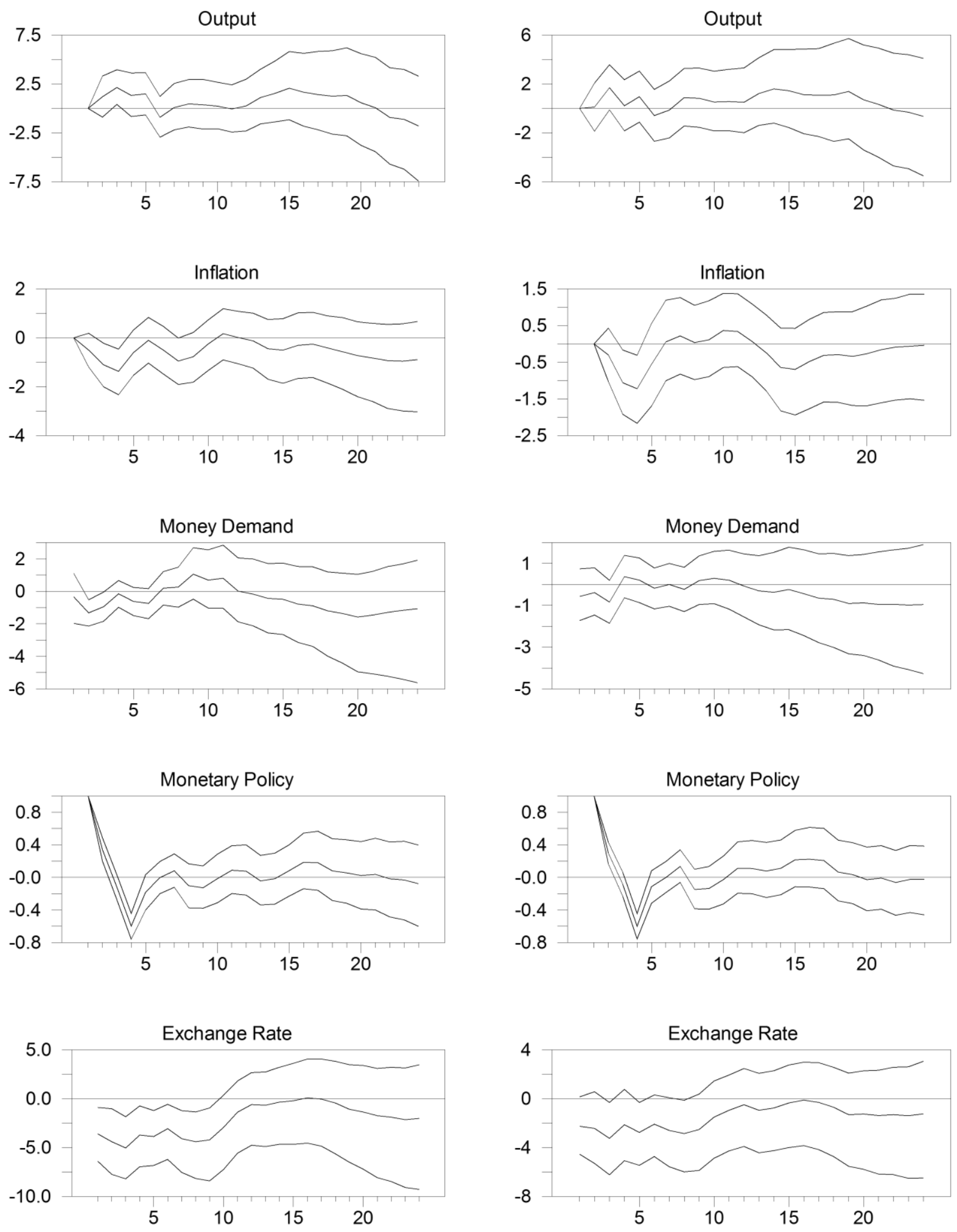
The statistical significance of impulse response is examined using the Bayesian Monte Carlo integration in RATS. The Random Walk Metropolis Hastings method is used to draw 10,000 replications for the over-identified SVAR model. The 0.16 and 0.84 fractiles correspond to the upper and lower dashed lines of the probability bands (see Doan (2013)).

From model 1, we observe monetary policy shocks have no initial impact on oil price. However, we subsequently observe growth in oil price, especially between the $10^{\text {th }}$ and $15^{\text {th }}$ month. The fact that major oil-importing countries, such as India, can influence price is not surprising. Policy shocks hardly affects the fed fund rate. Monetary policy shocks appear to have a short-lasting impact on industrial production. We observe a hump-response of industrial production to a monetary policy shock during the first 5 months. Since India's financial markets are not highly developed, the monetary transmission of financial signals into the real sectors of the economy is slow.

India is a large economy with missing middle, in the sense that the economy directly leapfrogged from the agriculture to service sector, bypassing the manufacturing or industrial sector. This structure could account for the immune or delayed response of industrial production to a monetary policy shock. The contraction in monetary policy has kept the growth in prices or inflation consistently below zero. We observe exchange rate overshooting in response to a monetary policy shock. The exchange rate appreciates on impact, before beginning to depreciate.

In model 2, contractionary monetary policy shocks are followed by a slightly increasing trend in oil prices with effects peaking at the $10^{\text {th }}$ and $15^{\text {th }}$ months. During the first 8 months, monetary policy shocks have negligible impact on the federal fund rate, followed by increasing funds rate. The response of industrial production to a monetary policy shock is insignificant. Following the shock, price growth remains initially negative, but positive price growth appears between the $6^{\text {th }}$ and the $12^{\text {th }}$ month. The impact of the policy shock seems to be short-lived. Following monetary policy shocks, money demand, measured using the simple-sum aggregates, exhibits mild growth with the effect peaking between the $10^{\text {th }}$ and $14^{\text {th }}$ months. Exchange rate appreciates following a monetary policy shock with delayed overshooting.

The SVAR models generally perform better than the recursive models, and models with the Divisia monetary aggregates perform better than models with the simple-sum monetary aggregates. We compare across Divisia M3 and simple-sum M3 with models including either the world price of oil or the world price of commodities. The Divisia results were better than the simple-sum results. This holds true for other available Indian Divisia aggregates. Relative to the four puzzles, Brischetto and Voss (1999) argue that resolving at least the price puzzle and exchange rate puzzle should be viewed as the minimum, and indeed our model is able to eliminate both of those puzzles. As evident from the impulse response diagrams, the SVAR model with Divisia are very successful.

Our results are robust to different numbers of lags and to different measures of variables, such as the consumer price index versus the wholesale price index, different measures of money as the 
monetary aggregate, and the world price of commodities versus the world price of oil as the world variable. The results also remain robust to different groupings of variables and to different samples or sub-periods

\subsection{Variance Decomposition}

In this section we provide the variance decomposition for the selected models displayed in Table 3. ${ }^{8}$ In models 1 and 2 we compare across the two monetary aggregates, simple-sum M3 and Divisia M3 (DM3), with world oil price as the contemporaneously exogenous world variable. In models 6 and 7 we compare across the same two monetary aggregates, but with the world price of commodities as the contemporaneously exogenous world variable.

\begin{tabular}{|c|c|c|c|c|c|c|c|}
\hline \multicolumn{8}{|c|}{ Table 3: Forecast Error Variance Decomposition (FEVD) Analysis } \\
\hline \multicolumn{8}{|c|}{$\begin{array}{c}\text { Forecast Error Decomposition: Contribution of Monetary Policy Shocks to Exchange Rate } \\
\text { Variation (in percentages) }\end{array}$} \\
\hline Month & Model 1 & Model 2 & Model 4 & Model 5 & Model 6 & Model 7 & Model 10 \\
\hline 1 & 15.968 & 5.706 & 17.312 & 23.97 & 21.093 & 8.025 & 28.417 \\
\hline 2 & 17.104 & 5.453 & 18.458 & 25.165 & 22.70 & 7.754 & 29.890 \\
\hline 3 & 19.67 & 7.51 & 20.891 & 28.292 & 25.428 & 10.102 & 33.094 \\
\hline 10 & 14.954 & 6.786 & 15.665 & 17.92 & 21.255 & 7.967 & 25.158 \\
\hline 11 & 14.354 & 6.317 & 15.05 & 17.134 & 20.128 & 7.471 & 24.007 \\
\hline 12 & 13.945 & 5.935 & 14.621 & 16.548 & 18.953 & 7.091 & 22.667 \\
\hline 22 & 10.993 & 4.635 & 11.379 & 13.183 & 14.331 & 4.875 & 17.974 \\
\hline 23 & 10.378 & 4.602 & 10.713 & 12.387 & 13.900 & 4.667 & 17.468 \\
\hline 24 & 9.773 & 4.583 & 10.073 & 11.589 & 13.540 & 4.471 & 17.053 \\
\hline
\end{tabular}

In model 1 , the interbank interest rate is the monetary policy variable, while DM3 acts as an informational indictor variable, measuring the flow of monetary services in the economy's transmission mechanism. Following the monetary policy shock, inclusion of DM3 helps the interest rate explain about $16 \%$ of the exchange rate fluctuation during the $1^{\text {st }}$ month and $19.7 \%$ during the $3^{\text {rd }}$ month. Even after 10 months, the policy variable can explain almost $15 \%$ of the exchange rate fluctuation. Interestingly, $10 \%$ of the exchange rate fluctuation is still explained by the interest rate, 24 months after the monetary policy shock.

Model 2 has world oil price as the exogenous world variable and simple-sum M3 as the monetary aggregate. The monetary policy variable is the interbank rate of interest. Following the monetary policy shock, inclusion of simple-sum M3 helps the interest rate to explain $5.7 \%$ of the exchange rate fluctuation during the $1^{\text {st }}$ month and $7.5 \%$ during the $3^{\text {rd }}$ month. After 10 months, the policy variable can explain about $6.8 \%$ of the exchange rate fluctuation. About $5 \%$ of the exchange rate fluctuation is explained by the interest rate, 24 months after the monetary policy

\footnotetext{
${ }^{8}$ The result for other models are available upon request.
} 
shock. Comparing with the Divisia monetary aggregate result in model 1 , we find that the information content of DM3 is substantially higher than that of simple-sum M3.

Model 6 has the world commodity price as the exogenous variable and the DM3 as the monetary aggregate. The monetary policy variable is the interbank rate of interest. Following the monetary policy shock, inclusion of DM3 as an informational variable permits the interest rate to explain $21 \%$ of the exchange rate fluctuation during the $1^{\text {st }}$ month and $25.428 \%$ during the $3^{\text {rd }}$ month. After 10 months following the shock, the policy variable can explain $21 \%$ of the exchange rate fluctuation. Interestingly, $13.5 \%$ of the exchange rate fluctuation is still explained by the interest rate after 24 months following the monetary policy shock. The variance decomposition analysis shows that inclusion of the monetary aggregate, especially Divisia money, permits the policy rate to explain high percentages of the exchange rate fluctuation. Use of the world commodity price, instead of the world oil price, permits monetary policy to explain higher percentages of the exchange rate fluctuation, as seen by comparing models 1 and 6.

The world commodity price is the exogenous variable in model 7, while simple-sum M3 is the monetary aggregate. The monetary policy variable is the interbank rate of interest. Inclusion of simple-sum M3 permits the interest rate to explain about $8 \%$ of the exchange rate fluctuation during the $1^{\text {st }}$ month and $10 \%$ during the $3^{\text {rd }}$ month, following the monetary policy shock. After 10 months, the policy variable can explain $8 \%$ of the exchange rate fluctuation. About $5 \%$ of the exchange rate fluctuation is explained by the interest rate after 24 months. The variance decomposition analysis shows that simple-sum M3 is substantially less successful that DM3 in explaining the exchange rate fluctuation.

In model 10 the world commodity price is the exogenous variable, and DM2 is the monetary aggregate. The monetary policy variable is the interbank rate of interest. DM2 acts as an informational variable permitting the interest rate to explain $28 \%$ of the exchange rate fluctuation during the $1^{\text {st }}$ month and $33 \%$ during the $3^{\text {rd }}$ month, following the monetary policy shock. After 10 months, the policy variable can explain $25 \%$ of the exchange rate fluctuation. Even 24 months after the monetary policy shock, $17 \%$ of the exchange rate fluctuation is still explained by the interest rate. Comparing among the Divisia aggregates at the different levels of aggregation, we find that DM2 works the best, followed by DL1 and DM3.

Comparing all of our models, we find that the best is the one that includes the world commodity price and Divisia M2. In general, we find that DM2 consistently works the best, followed by DL1 and then DM3. Among the simple sum monetary aggregates, the narrowest works better than the broad simple sum aggregates, but not as well as the Divisia.

\subsection{Flip-Flop Analysis}

In this section we do a flip-flop analysis. Figure 9 represents the fluctuations in the fundamental variables --- exchange rate, inflation, and economic activity --- being explained by the policy variable. Figure 10 displays how much of each of the fundamental variables can be explained by 
movements in the policy variable. We have analyzed the first 10 models. To conserve on journal space, we display the results only with model $5 .^{9}$

In Figure 9, the monetary policy shock can explain $25-30 \%$ of the fluctuation in the exchange rate during the first 6 months, and then $25-15 \%$ between the $6^{\text {th }}$ and $18^{\text {th }}$ month. Monetary policy shocks explain $5-10 \%$ of the prices fluctuations throughout most of the trajectory. However, the monetary policy shock can explain less than $5 \%$ of the fluctuation in real variables, such as industrial production represented by GDP. The weak monetary transmission mechanism might be a consequence of India's underdeveloped financial sector.

Figure 9: Monetary policy explaining fundamental variables

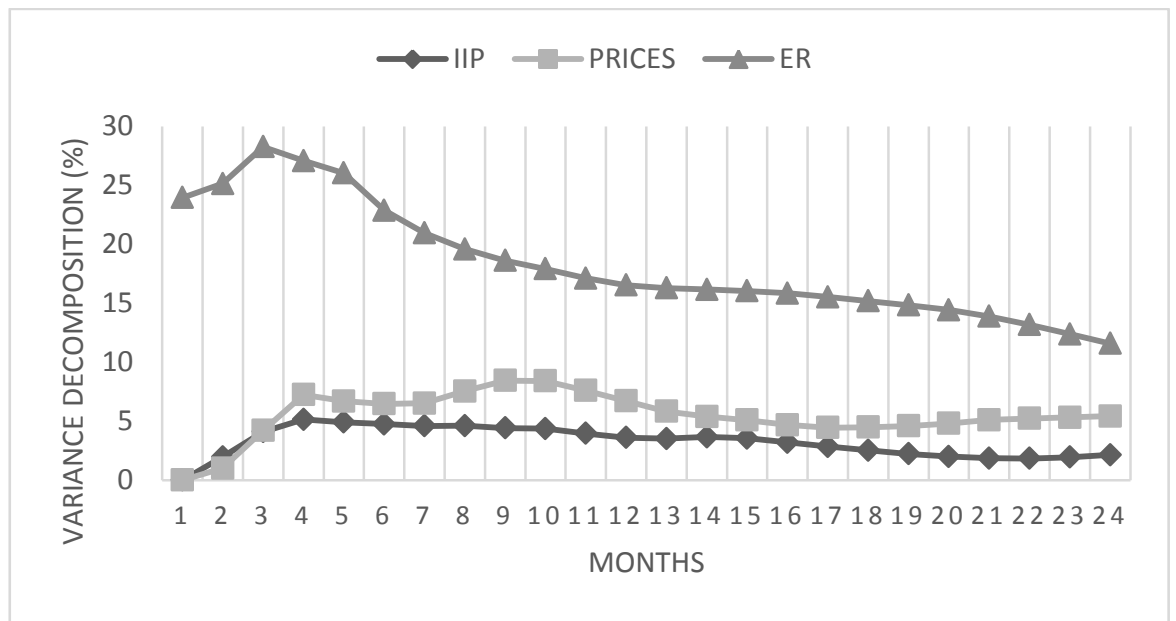

${ }^{9}$ The result for other models are available upon request. 


\section{Figure 10: Fundamental variables explaining monetary policy}

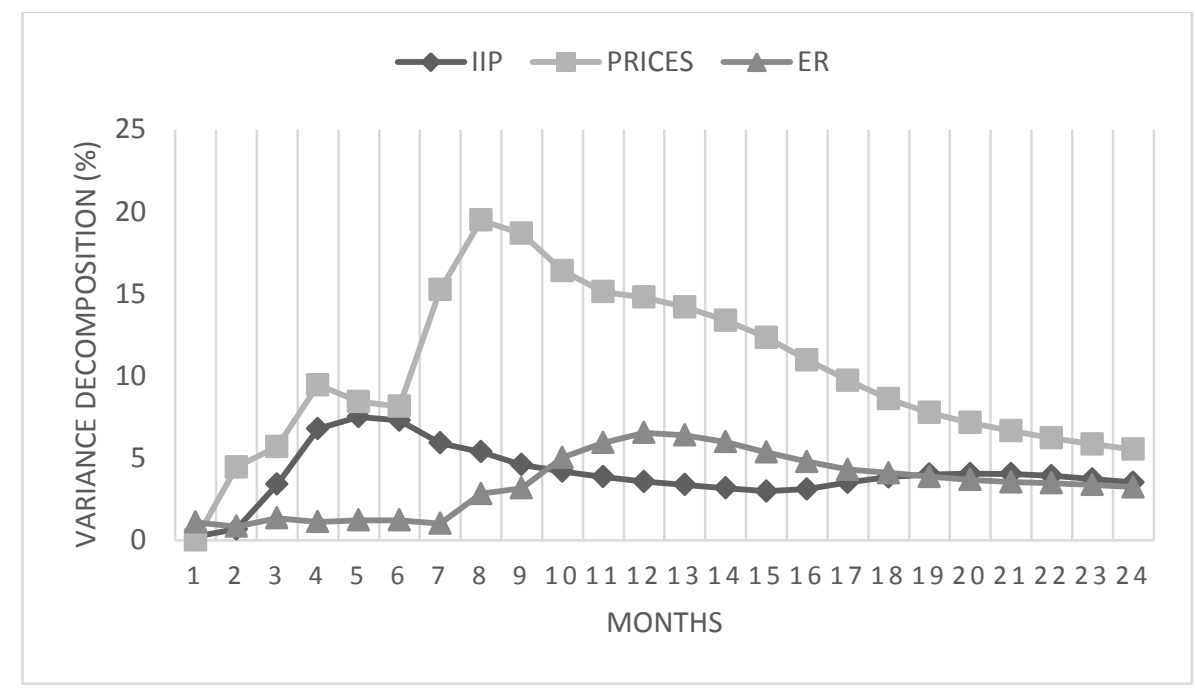

According to Figure 10, the central bank in India seems to set its monetary policy rule based on inflation-targeting as a primary objective. Close to $20 \%$ of the fluctuation in the monetary policy variable is explained by inflation during the $8^{\text {th }}$ month following the shock. For the first 10 months, GDP explains more of the fluctuation in the policy variable than nominal exchange rate (NER) does. But for the next 8 months, NER explains more of that fluctuation. GDP and NER can account for $3 \%-7 \%$ of the fluctuation in the interest rate.

In summary, there is a weak link between the nominal-policy variable and real-economic activity, and the Indian monetary authority had inflation-targeting as one of its primary goals. These results are robust, across different time periods, dissimilar monetary aggregates, and diverse exogenous model specifications.

\subsection{Forecast Statistics for Exchange Rate}

In this section we compare different VAR models in terms of their ability to perform out-ofsample exchange rates forecasts. The criteria used to measure forecast errors are Root Mean Square Error (RMSE) and Theil U statistic. We calculate "out-of-sample" forecasts within the data range by using the Kalman filter to estimate the model up to the starting period of each set of forecasts. Our purpose is not to find the best forecasting model, but to determine how the forecasting performance changes, when we add money to the system and when we use different measures of money. The choice of the sample is driven by the availability of Ramachandran, Das, and Bhoi's (2010) Indian Divisia data, which end at 2008:6. We estimate the model through 2006:6 and do updates for the period 2006:7 to 2008:6 using the Kalman filter for the 24 steps. Forecast performance statistics are compiled over that period. 
We begin by computing

$$
e_{i t}=y_{t}-\hat{y}_{i t},
$$

where $\hat{y}_{i t}$ is the forecast at step $t$ from the $i^{\text {th }}$ call, and $y_{t}$ is the observed value of the dependent variable. Let $N_{t}$ be the number of times that a forecast has been computed for horizon $t$, with $i=1,2, \cdots, N_{t}$. Then the Room Mean Square Error of the forecasts is

$$
R M S E_{t}=\sqrt{\frac{\sum_{i=1}^{N_{t}} e_{i t}^{2}}{N_{t}}}
$$

In contrast, the RMSE of the no-change (martingale) forecasts are

$$
R M S E N C F_{t}=\sqrt{\frac{\sum_{i=1}^{N_{t}}\left(y_{i t}-y_{i 0}\right)^{2}}{N_{t}}}
$$

where $y_{i 0}$ is the "naive" or flat forecast --- the value of the dependent variable at the start period for the $i^{\text {th }}$ call.

Theil's U statistic (Doan (2013)) is

$$
U_{t}=\frac{R M S E_{t}}{R M S E N C F_{t}}
$$

which is a unit free measurement. A value less than one indicates a good forecasting model. 
Table 4 compares the model with simple-sum M3 versus Divisia M3 with 24- step ahead forecasts. The model with Divisia M3 produces lower RMSE and Theil $U$ values than the model with simple-sum M3. The difference between the RMSE and Theil $U$ grows over time, perhaps suggesting that Divisia M3 facilitates longer-horizon forecasting.

\begin{tabular}{|lllll|}
\hline \multicolumn{5}{|c|}{ Table 4: Forecast Statistics for Exchange rate } \\
\hline STEP & RMSE & RMSE & Theil U & Theil U \\
\hline 1 & 0.016817268 & 0.0168186 & 0.9407059 & 0.940740 \\
\hline 2 & 0.027939798 & 0.0279426 & 0.9465474 & 0.946622 \\
\hline 3 & 0.035327661 & 0.0353301 & 0.94694318 & 0.94701555 \\
\hline 4 & 0.04509268 & 0.045096935 & 0.97101692 & 0.97110852 \\
\hline 5 & 0.053015259 & 0.053020313 & 0.98133839 & 0.98143195 \\
\hline 6 & 0.061130186 & 0.061135251 & 0.98933159 & 0.98941357 \\
\hline 7 & 0.07159638 & 0.071601885 & 1.00796044 & 1.00803795 \\
\hline 8 & 0.081620156 & 0.081625622 & 1.02052515 & 1.02059349 \\
\hline 9 & 0.090236999 & 0.090240718 & 1.01969010 & 1.01973213 \\
\hline 10 & 0.101070039 & 0.101074766 & 1.03026120 & 1.03030939 \\
\hline 11 & 0.109619074 & 0.109625888 & 1.03736232 & 1.03742681 \\
\hline 12 & 0.115919549 & 0.115927138 & 1.04535736 & 1.04542579 \\
\hline 13 & 0.122422252 & 0.122431367 & 1.05291817 & 1.05299657 \\
\hline 14 & 0.125861402 & 0.125869018 & 1.05283130 & 1.05289501 \\
\hline 15 & 0.131125827 & 0.131134336 & 1.05436936 & 1.05443778 \\
\hline 16 & 0.135008923 & 0.135019462 & 1.05461511 & 1.05469744 \\
\hline 17 & 0.13596275 & 0.135975093 & 1.05532448 & 1.05542028 \\
\hline 18 & 0.136027792 & 0.13604202 & 1.05607557 & 1.05618603 \\
\hline 19 & 0.134682711 & 0.134698657 & 1.05710163 & 1.05722679 \\
\hline 20 & 0.130837069 & 0.130854786 & 1.06003547 & 1.06017902 \\
\hline 21 & 0.125022931 & 0.125042025 & 1.06517634 & 1.06533902 \\
\hline 22 & 0.118076898 & 0.118096956 & 1.07450819 & 1.07469072 \\
\hline 23 & 0.094336989 & 0.094357902 & 1.10405841 & 1.10430315 \\
\hline 24 & 0.08290196 & 0.082923123 & 1.13793843 & 1.13822892 \\
\hline & & & & \\
\hline
\end{tabular}

The results imply the following: the exchange rate forecasting model with money performed better than the model without money, and the exchange rate forecasting model with Divisia money performed better than the model with simple-sum money.

The forecast graphs, figures 11 and 12, are obtained through Gibbs sampling on a Bayesian VAR with a "Minnesota" prior. The sequential likelihood ratio test selects 13 lags for the model for the given period. We hold back a part of the data to use for evaluating forecast performance. The graph forecasts 24 steps ahead with a +/- two standard error band using 2500 draws. The out of 
the sample simulations accounts for two sources of uncertainty in forecasts: both the uncertainty regarding the coefficients (handled by Gibbs sampling) and the shocks during the forecast period (see Doan (2012)).

\section{Figure 11: Out of sample forecast graph (Model without money and Divisia M3)}

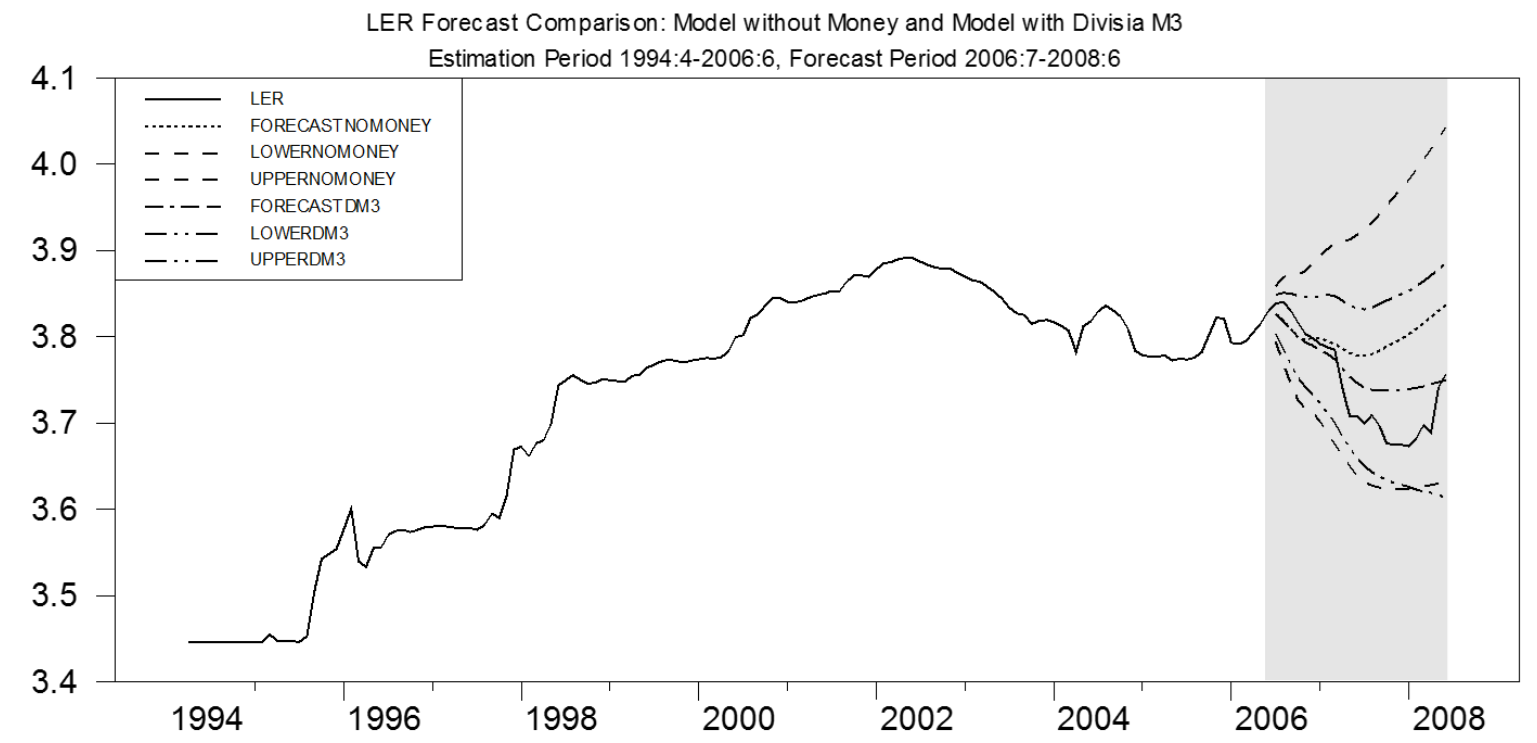

Figure 11 represents the out of sample forecasting graph, and compares the model without money to the model with Divisia M3. The model forecast with Divisia M3 stays closer to the $\log$ of the actual exchange rate (LER) value. The model forecast with no money clearly diverges from actual value over time. The forecast band for the model with Divisia M3 lies within the forecast band for the model with no money, implying that model with Divisia M3 can predict the exchange rate with greater precision.

Figure 12 represents the out of sample forecasting graph for the log of exchange rate and compares the model with simple-sum M3 to the model with the Divisia M3. The model forecast with Divisia M3 remains closer to the actual LER value. The model forecast with simple-sum M3 diverges from the actual value over time. The forecast band for the model with Divisia M3 is narrower than the forecast band with simple-sum M3. This result reflects higher forecast accuracy in models with Divisia money than with simple sum money.

We have evaluated the relative performance of models using the out-of-sample forecasting graphs and the RMSE and Theil $U$ statistic. We conclude that the model with Divisia M3 performs better than with simple-sum M3, which in turn does better than the model with no money. This conclusion applies to forecasting exchange rates both in the short-run and the long-run, and the result is robust to different levels of monetary aggregation. 


\section{Figure 12: Out of sample forecast graph (Model with simple sum M3 and Divisia M3)}

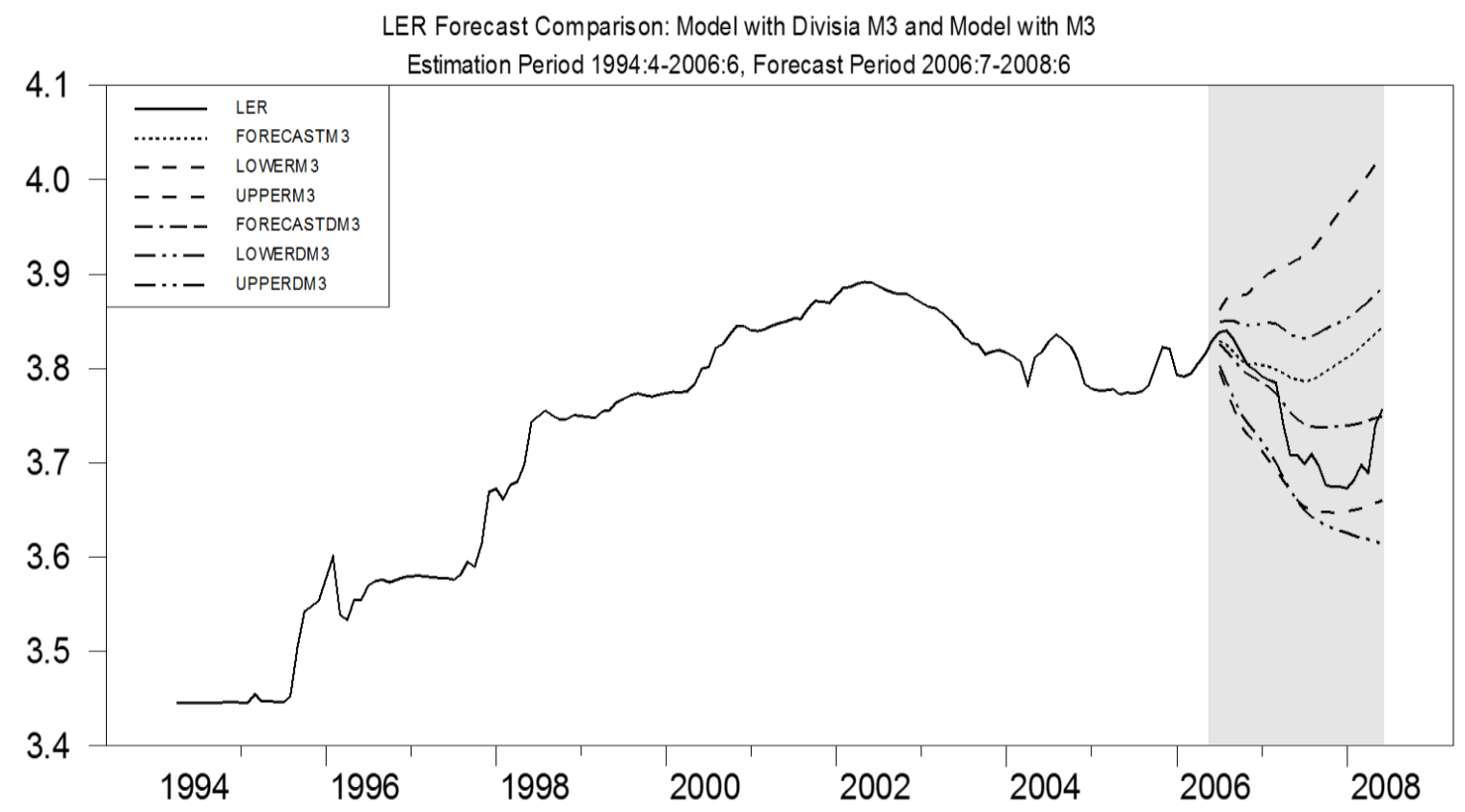

\section{Conclusion}

In this paper, we have applied the aggregation theoretic Divisia monetary aggregate in the exchange rate determination for India. We compare across models with and without money.

Our SVAR model was found to be free of the price puzzle and the exchange rate puzzle. We compared the contemporaneous SVAR with the recursive model. In the recursive model, both the price puzzle and the exchange rate puzzle appeared. Some minor evidence of the outputpuzzle in the SVAR did appear. For countries like India, with maturing financial markets, financial signals might be transmitted slowly to the real sectors. In that sense, the monetary transmission mechanism might be weak and delayed.

The variance decomposition analysis in our SVAR model provided further insights. We found that introduction of money added valuable information by explaining significantly more of the exchange rate fluctuations, when compared to the no-money model. In addition, Divisia money's explanatory power was higher than simple-sum money. Our out-of-sample forecasting results were analyzed and compared using the RMSE and Theil U statistics. In general, the inclusion of money lowered the RMSE values, and Divisia money model did better than simple-sum model.

Finally, we did flip-flop analysis, by which we provided a pictorial representation of how much monetary policy in India can explain exchange rate, inflation, and production movements, as well as how much these variables can explain movements in the policy variable. Our results showed that during the estimation period 2000(1)-2008(1), monetary policy is able to explain 
most of the exchange rate fluctuations, followed by inflation fluctuations, but little of the output movements. Conversely, inflation is able to explain most of the policy-variable changes. This leads us to believe that the central bank of India emphasized inflation-targeting.

We conclude that inclusion of Divisia monetary aggregates in an open economy model helps substantially in explaining exchange rate response to central bank interest rate shocks and in resolving the paradoxes that have plagued the literature on exchange rate fluctuations.

\section{References}

Anderson, R. G. and K. A. Kavajecz, 1994. “A Historical Perspective on the Federal Reserve's Monetary Aggregates: Definition, Construction, and Targeting," Federal Bank of St. Louis Review 76, 1-31.

Assenmacher-Wesche, K. and S. Gerlach, 2006. "Interpreting Euro Area Inflation at High and Low frequencies,” Bureau of International Settlement Working Paper, n. 195.

Barnett. W. A., 1980. Economic Monetary Aggregate: An Application of Index Number and Aggregation Theory. Journal of Econometrics 14, September, 11-48.

Barnett, W. A., 2012. Getting It Wrong: How Faulty Monetary Statistics Undermine the Fed, the Financial System, and the Economy, MIT Press, Cambridge, MA.

Barnett. W. A. and Chang Ho Kwag, 2006. Exchange Rate Determination from Monetary Fundamentals: an Aggregation Theoretic Approach, Frontiers in Finance and Economics 3, n. 1, 29-48.

Barnett, W. A. and M. Chauvet, 2011. Financial Aggregation and Index Number Theory, World Scientific, Singapore.

Barnett, W. A. and A. Serletis, 2000. The Theory of Monetary Aggregation, Elsevier, Amsterdam

Barnett, W. A., Chauvet, M., and D. Leiva-Leon, 2015. "Real-Time Nowcasting of Nominal GDP Under Structural Break," Journal of Econometrics, forthcoming.

Bernanke, B., 1986. “Alternative Explanations of Money Income Correlation.” In: Brunner, K. and A. H. Meltzer (Eds.), Real Business Cycles, Real Exchange Rates, and Actual Policies, Carnegie-Rochester Series on Public Policy 25, North Holland, Amsterdam, 49-99.

Belongia, M. and P. Ireland, 2012. "Quantitative Easing: Interest Rates and Money in the Measurement of Monetary Policy.” Boston College Working Paper. 
Brischetto, A. and G.Voss, 1999. "A Structural Vector Autoregression Model of Monetary Policy in Australia”. Research Discussion Paper 1999-11, Reserve Bank of Australia.

Bruggeman, A, Camba-Mendez., G, Fischer, B, and J. Sousa, 2005. "Structural Filters for Monetary Analysis: the Inflationary Movements of Money in the Euro Area," ECB Working Paper, n. 470.

Chrystal, K. and R. MacDonald, 1995. "Exchange Rates, Financial Innovation and Divisia Money: the Sterling/Dollar Rate," Journal of International Money and Finance 14, 493-513.

Cochrane, J. H, 2007. "Inflation Determination with Taylor Rules: a Critical Review," NBER Working Paper, n. 13409.

Courtenay, S. and D. Thornton, 1987. "Solving the 1980s' Velocity Puzzle: A Progress Report," St. Louis Federal Reserve Review (August/September 1987), 175-204

Christiano. L. J, Motto. R, and M. Rostagno, 2007. “Two Reasons Why Money and Credit May Be Useful in Monetary Policy,” NBER Working Paper, n 13502.

Diewert, W., 1976. "Exact and Superlative Index Numbers," Journal of Econometrics 4, 115145.

Doan, T., 2013, RATS Manual, Version 8.3, Estima, Evanston, IL.

Doan T., 2012, RATS Handbookfor Bayesian Econometrics, Estima, Evanston, IL.

Drake, L. and T. C. Mills, 2005. "A New Empirically Weighted Monetary Aggregate for the United States," Economic Inquiry 43, No.1, 138-157.

Goodfriend, M. and M. J. Lacker, 1999. "Limited Commitment and Central Bank Lending," Economic Quarterly - Federal Reserve Bank of Richmond, Fall, 1-27.

Hamilton, J. D. (1994), Time Series Econometrics, Princeton U. Press, Princeton, NJ.

Ireland, P., 2001a. "Sticky-Price Models of the Business Cycle - Specification and Stability," Journal of Monetary Economics 47, 3-18.

Ireland, P., 2001b. "Money's Role in the Monetary Business Cycle," Working Paper 8115, National Bureau of Economic Research.

Jansen, E. S., 2004. “Modelling Inflation in Euro Area,” ECB Working Paper, n. 322.

Kim, S. and N. Roubini, 2000. "Exchange Rate Anomalies in the Industrial Countries: A Solution with a Structural VAR Approach," Journal of Monetary Economics 45(3), pp. 561-586. 
Leeper, E. and J. Roush, 2003. "Putting 'M' Back in Monetary Policy," Journal of Money, Credit and Banking 35, No.6, pp. 1217-1256.

Masuch, K. S., Nicoletti-Altimari, S, and M. Rostagno, 2003. "The Role of Money in Monetary Policy Making,” Bureau of International Settlement Working Paper, n 1

Nelson, E, 2003. "The Future of Monetary Aggregates in Monetary Policy Analysis," Journal of Monetary Economics vol. 50(5), 1029-1059.

Nicoletti-Altimari, S, 2001. "Does Money Lead Inflation in Euro Area?" ECB Working Paper, n. 63.

Ramachandran, M, Das, R., and B. Bhoi, 2010. "The Divisia Monetary Indices as Leading Indicators of Inflation," Reserve Bank of India Development Research Group Study No.36, Mumbai.

Schunk, D., 2001. "The Relative Forecasting Performance of the Divisia and Simple Sum Monetary Aggregate," Journal of Money, Credit and Banking 33, 272-283.

Sims, C. A., 1980, “Macroeconomics and Reality," Econometrica 48, 1-48.

Taylor, J., 1999. Monetary Policy Rules, University of Chicago Press, Chicago, IL.

Trecoci, C. and J. L. Vega, 2002. "The Information Content of M3 for Future Inflation in Euro Area," Weltwirtschaftliches Archiv 138 (1), 22-53. 


\section{Appendix}

\begin{tabular}{|c|c|c|c|c|c|c|}
\hline \multicolumn{7}{|c|}{$\begin{array}{c}\text { Table A } \\
\text { Lag Selection Test }\end{array}$} \\
\hline \multirow[t]{2}{*}{ Model } & \multicolumn{2}{|c|}{ Test for 7 vs 6 Lags } & \multicolumn{2}{|c|}{ Test 6 vs 5 Lags } & \multicolumn{2}{|c|}{ Test 5 vs 4 Lags } \\
\hline & $\chi^{2}$ & $\begin{array}{c}\text { Significance } \\
\text { Level }\end{array}$ & $\chi^{2}$ & $\begin{array}{c}\text { Significance } \\
\text { Level }\end{array}$ & $\chi^{2}$ & $\begin{array}{c}\text { Significance } \\
\text { Level }\end{array}$ \\
\hline Model 1 & 38.488243 & 0.85999185 & 73.662305 & 0.01288129 & 57.877533 & 0.18031970 \\
\hline Model 2 & 38.238935 & 0.86648886 & 54.117803 & 0.28541031 & 69.431849 & 0.02893017 \\
\hline Model 3 & 53.002955 & 0.32246811 & 78.648694 & 0.00456914 & 64.755425 & 0.06514492 \\
\hline Model 4 & 39.090622 & 0.84354759 & 74.325737 & 0.01127813 & 58.111194 & 0.17483359 \\
\hline Model 5 & 49.714073 & 0.44468077 & 80.313435 & 0.00317348 & 70.370490 & 0.02431895 \\
\hline Model 6 & 44.884835 & 0.64059402 & 76.544547 & 0.00714969 & 52.272749 & 0.34806341 \\
\hline Model 7 & 34.424993 & 0.94307877 & 60.173485 & 0.13157340 & 67.103896 & 0.04383014 \\
\hline Model 8 & 55.083386 & 0.25542317 & 83.970999 & 0.00138233 & 60.157528 & 0.13187352 \\
\hline Model 9 & 45.679504 & 0.60854031 & 76.434126 & 0.00731667 & 52.450227 & 0.34175099 \\
\hline Model 10 & 53.620973 & 0.30161218 & 82.322186 & 0.00202066 & 65.886271 & 0.05398571 \\
\hline
\end{tabular}

